\title{
O USO DO TEXTO NARRATIVO PARA O ENSINO DAS CAUSAS DE EXTINÇÃO DAS PLANTAS
}

\author{
Gabriel Gonçalves Ribeiro Silva ${ }^{1}$
}

\author{
Antonio Fernandes Nascimento Júnior ${ }^{2}$
}

\begin{abstract}
RESUMO
Neste trabalho é demonstrado o potencial da estratégia pedagógica texto narrativo no ensino de ciências e na educação ambiental. É discutida a importância do estudo de conceitos relacionados ao meio ambiente, de um ponto de vista crítico, especialmente na atualidade, aliando a preocupação com a preservação do meio por motivos ambientais e ecológicos, porém também motivos sociais, incluindo elementos culturais, medicinais e econômicos. Assim, para auxiliar neste estudo em salas de aula dos ensinos fundamental e médio, o texto narrativo é apresentado como estratégia que, além de aproximar a discussão ambiental e social do aluno, também oferece possibilidades interessantes, por exemplo o diálogo do texto com a literatura em geral e o estímulo da criatividade dos alunos. É então relatada uma aula experimental realizada com esta estratégia, que demonstra sua eficácia, que dialoga com a literatura existente para solidificar a justificativa do uso do texto narrativo dentro da sala de aula, no ensino fundamental ou médio. É utilizado o tema de causas de extinção das plantas durante a aula. Com base no tema, foram discutidos com os alunos alguns dos motivos pelas quais as plantas podem ser extintas, e logo depois eles desenvolveram, individualmente, textos narrativos relacionados ao assunto. Ao final da aula, pode-se perceber que o texto narrativo foi eficaz no auxílio da compreensão do tema pelos alunos.
\end{abstract}

PALAVRAS-CHAVE: Metodologias alternativas; Educação Ambiental; Texto Narrativo;

\section{USE OF NARRATIVE TEXT IN THE TEACHING OF SCIENCE AND ENVIRONMENTAL EDUCATION}

\begin{abstract}
This paper demonstrates the potential of the narrative text as a pedagogical strategy in science education and environmental education. It discusses the importance of the study of concepts related to the environment, of a

\footnotetext{
${ }^{1}$ Graduando em Licenciatura em Ciências Biológicas, Bolsista do Programa Institucional de Bolsas de Iniciação a Docência (PIBID), Universidade Federal de Lavras (UFLA-MG), gabrielgrsilva@yahoo.com.br ${ }^{2}$ Professor Adjunto, Laboratório de Educação Científica e Ambiental (LECA), Departamento de Biologia (DBI), Universidade Federal de Lavras (UFLA-MG), toni_nascimento@yahoo.com.br
} 
critical point of view, especially nowadays, combining concern for the preservation of the environment for ecological reasons, but also social reasons, including cultural, medicinal and economic elements . Considering this, to assist this study in classrooms of elementary and high school, the narrative text is presented as a strategy that, in addition to approach environmental and social discussion to the student, it also offers interesting possibilities, for example its relation with literature in general and the stimulation of the creativity of the students. It is then reported an experimental class performed with this strategy, which demonstrates its effectiveness, and which dialogues with the existing literature to solidify the justification of the use of narrative text within the classroom in elementary or middle school. The theme of causes of extinction of plants is used during that class. Based on the theme, it were discussed with the students some of the reasons by which plants may become extinct, and soon after they developed individually narrative texts related to the subject. At the end of class, one can see that the narrative text was effective in aiding the understanding of the subject by the students.

\section{EL USO DE TEXTO NARRATIVO EN LA ENSEÑANZA DE LA CIENCIA Y EN LA EDUCACIÓN AMBIENTAL}

\section{RESUMEN}

Este trabajo demostró el potencial de la estrategia pedagógica texto narrativo en la educación científica y la educación ambiental. Se habló de la importancia del estudio de los conceptos relacionados con el medio ambiente, un punto de vista crítico, especialmente hoy en día, la combinación de la preocupación por la preservación de las razones ambientales y ecológicas, sino también motivos sociales, incluyendo elementos culturales, medicinales y económicos. Por lo tanto, en este estudio para ayudar en las aulas de la escuela primaria y secundaria, el texto narrativo se presenta como una estrategia que, además de abordar la discusión ambiental y social de los estudiantes, sino que también ofrece posibilidades interesantes, por ejemplo, el texto de un diálogo con la literatura en general, y la estimulación de la creatividad de los estudiantes. Se informa a continuación, una clase experimental realizado con esta estrategia, lo que demuestra su eficacia, que dialoga con la literatura existente para solidificar la justificación del uso de textos narrativos en el aula en la escuela primaria o secundaria. Se utiliza el tema de las causas de extinción de las plantas durante la clase. Basado en el tema, se discutieron con los estudiantes algunas de las razones por la que las plantas podrían extinguirse, y poco después se desarrollaron individualmente textos narrativos relacionados con el tema. Al final de la clase, se puede ver que el texto narrativo fue eficaz para ayudar a la comprensión de la materia por los alumnos.

PALABRAS-CLAVE: Metodologías alternativas; Educación Ambiental; Texto narrativo;

\section{INTRODUÇÃO}

A extinção de plantas é um dos fatores que podem causar impactos significativos à população humana, além dos impactos puramente ambientais, já apresentados frequentemente para a sociedade. Melo et al (2011) menciona Lychnophora ericoides como uma planta atualmente considerada como espécie 
vulnerável, devido a coleta predatória e a degradação do ambiente em que esta se insere, especialmente por se tratar de uma espécie endêmica. Nesta região, a planta é popularmente conhecida como "arnica" (dentre outros nomes), e é comercializada e utilizada, por exemplo, como anti-inflamatório, no tratamento de varizes, contusões e hematomas, sendo assim utilizada culturalmente por suas propriedades medicinais.

As experiências pedagógicas do ensino de ciências em geral e, em particular, da Botânica caminham no sentido de valorizar as estratégias que inserem aspectos culturais, éticos, de saúde e outros na contextualização do conteúdo conceitual a ser ensinado na escola (BRASIL, 1998). No caso acima citado, seria importante trazer, para dentro da sala de aula, a preocupação com espécies como esta, visando mostrar ao aluno não somente a importância ecológica e biológica da planta, mas também sua importância cultural, medicinal, econômica e, portanto, social.

Deste modo, torna-se necessário que o professor se atente às estratégias que fujam ao método tradicional de ensino, de modo a facilitar a aproximação de conteúdo conceitual com os aspectos sociais do tema, buscando gerar interesse do educando pelo assunto tratado em sala e, portanto, tornando o ensino mais eficiente e até mesmo divertido.

\section{Algumas experiências não convencionais para o ensino do tema}

$\mathrm{Na}$ literatura, são encontradas várias estratégias para facilitar a aproximação destes conhecimentos dos educandos. Santos e Piassi (2010) utilizaram um filme de animação (WALL-E) no sentido da educação ambiental, possibilitando também o trabalho com os temas transversais Ética, Pluralidade Cultural, Meio Ambiente, Saúde e Trabalho e Consumo. Algumas etapas foram seguidas pelos autores, que elaboraram um roteiro de aulas, primeiramente conversando com os alunos sobre o porque da exibição do filme, com o objetivo de direcionar sua atenção para um objetivo pedagógico. Logo depois, houve a exibição do filme e uma discussão sobre ele, seguido de um debate em grupo e a realização de atividades. Silva et al (2011) mostram o potencial dos livros para trazer a discussão sobre ciência, utilizando como exemplo o clássico livro Macunaíma. 
Silva (2012) propõe o uso da música para o ensino de ecologia, com ênfase no aquecimento global. Foi desenvolvida uma atividade para alunos do terceiro ano do Ensino Médio. Foram apresentadas algumas questões sobre esses assuntos para os alunos, após a apresentação de algumas músicas que continham esses temas, e depois foi realizada uma coleta de dados. Com as observações realizadas e a análise dos dados obtidos, o autor comprovou a contribuição da música sobre a aprendizagem dos alunos acerca do tema aquecimento global. Com a análise da canção e de sua letra, os educandos conseguiram identificar o impacto causado pelo aumento do efeito estufa, além de refletir sobre a importância da preservação do meio ambiente, simultaneamente socializando seus pontos de vista, de modo que a aula foi motivadora e dinâmica.

Jogos também são encontrados na literatura como estratégia de ensino de ecologia. Nascimento Júnior e Gonçalves (2013) realizaram uma oficina de jogos pedagógicos, escolhendo um dos jogos expostos durante a oficina para ser jogado pelos participantes, posteriormente pedindo aos participantes para que realizassem uma avaliação da prática. As avaliações e depoimentos ao final da atividade indicaram positivamente uma aplicabilidade da prática na sala de aula. Os participantes (em maioria) apontaram a atividade como diferenciada e motivadora, de modo que esta, além de aproximar os participantes dos animais presentes nos jogos, levou-os até o aprendizado dos conceitos ecológicos presentes na atividade, sobre os animais da região e suas características. Schalch et al (2012) também utilizaram jogos didáticos para construir estes conceitos.

Utilizando o processo investigativo, Oliveira e Correia (2013) realizaram aulas de campo com alunos do Ensino Médio para facilitar a aprendizagem sobre o ecossistema recifal. Foram aplicados questionários antes e depois das aulas de campo. Com o conjunto de informações obtidas ao decorrer das etapas, somados aos seus respectivos questionários, aplicados aos alunos dos $3^{\circ}$ anos envolvidos, os autores realizaram a quantificação das respostas dos educandos por questão e efetuaram a transformação destes dados em porcentagem, expressando-os em gráficos.

Carvalho e Macedo (2008) descrevem o uso de brincadeiras ligadas ao ensino de ecologia. Segundo os autores, brincadeiras, brinquedos e jogos estão intimamente ligados ao sentimento comunitário humano, auxiliando na diferenciação das mais 
diversas culturas no mundo, além de formas de relações, tradições e crenças, por meio da transmissão de experiências ou sentimentos de prazer, felicidade, descoberta, ganho, perda, dor ou realização enquanto grupo ou indivíduo membro de uma tribo. Ao tratar a ecologia através de brincadeiras, conceitos como fluxo de energia e de ciclagem de nutrientes podem se revelar para os participantes na medida em que estes entram no jogo. "Se aproximar dos conceitos ambientais através da cultura da brincadeira representa o fortalecimento do elo sagrado entre os Seres Humanos e a natureza" (CARVALHO; MACEDO, 2008, p.1)

\section{O texto narrativo como estratégia de ensino}

Segundo Galvão (2005), a narrativa, na forma oral ou escrita, constitui-se como um método investigativo na medida em que possibilita uma relação com conflitos contemporâneos. O mesmo afirmam Reis Neto et al (2014) quando apontam o caráter cultural da literatura em diálogo com os aspectos científicos do ensino de ciências.

Esta estratégia permite que sejam construídos, na sala de aula, conceitos dos mais variados junto com os alunos, enquanto permite que eles exercitem simultaneamente sua criatividade e habilidades linguísticas, na medida em que, ao aluno, é permitido utilizar a fantasia em seu texto, aliada a conceitos reais.

O uso do Texto Narrativo também é interessante pelo seu potencial cultural. Carvalho (2008, p.467) reconhece que a Biologia faz parte da literatura em livros do escritor Monteiro Lobato, apontando que alguns de seus livros podem ser usados para tratar de "traços biológicos como evolução, seleção natural, tamanho, classificação e organização natural”. Como desenvolvido adiante, é possível que a literatura possa se aliar a ferramenta tratada nesse trabalho para um resultado impressionante em sala.

O objetivo deste trabalho foi construir, aplicar e analisar o Texto Narrativo como estratégia capaz de trazer questões de cunho em uma aula experimental sobre Causas de Extinção das Plantas prevista no Conteúdo Básico Comum (CBC) do estado de Minas Gerais (MINAS GERAIS, 2007).

\section{RELATO DE AULA EXPERIMENTAL COM O USO DO TEXTO NARRATIVO}


Foi realizada uma aula utilizando o texto narrativo como estratégia, na disciplina de Metodologia do Ensino de Botânica do curso de Licenciatura em Biologia da Universidade federal de Lavras. Esta aula foi realizada ao final da disciplina, após algumas etapas de preparação que culminaram na aula per se.

\section{A justificativa para o ensino do Conceito}

As diversas importâncias da Botânica, especialmente no que se refere as causas de extinção das plantas, foram consideradas na elaboração da aula, sempre aliada à perspectiva destes conhecimentos aplicada na sociedade, formal ou informalmente, e não apenas para o conhecimento e curiosidade científicos, como por exemplo na utilização de chás medicinais, de forma mais diretamente observável, ou o impacto que barragens podem ocasionar na extinção de certas espécies, podendo causar a curto ou longo prazo prejuízos diversos para a população em geral (além dos possíveis danos para outros organismos daquele ambiente).

O tema de causas de extinção das plantas é previsto no CBC/MG para o terceiro ano do ensino médio, sobre o Tema 2: História de Vida na Terra, Tópico 22 (MINAS GERAIS, 2007). As causas da extinção das plantas, também se encontram inseridas nos Parâmetros Curriculares Nacionais, no contexto da preservação da biodiversidade e, ao mesmo tempo, na educação ambiental a partir do Tema Transversal Meio Ambiente (BRASIL, 1998).

\section{Identificação da Estratégia}

O Texto Narrativo tem por objetivo construir os conceitos a serem aprendidos junto com os alunos, enquanto exercitam simultaneamente sua criatividade e habilidades linguísticas, de forma divertida e estimulante, na medida em que ao aluno é permitido utilizar a fantasia em seu texto, aliada a conceitos reais.

\section{O desenvolvimento da aula}

A aula foi dividida em 3 momentos: 


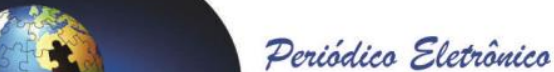

1:: Problematização com os alunos acerca de algumas causas de extinção de plantas.

$2^{\circ}$ : Construção de textos narrativos em grupos de 3 a 4 alunos.

3: Breve apresentação dos textos e discussão final.

Este planejamento foi, então, apresentado em um Simpósio realizado no Museu de História Natural da UFLA. Foram realizadas sugestões orais por parte dos alunos presentes as quais foram levadas em consideração para a modificação e elaboração final da aula, somadas ao plano original.

$\mathrm{Na}$ aula, primeiramente, foi feita uma problematização breve com os alunos sobre o que poderia causar a extinção das plantas. Logo após essa primeira etapa, foi distribuído aos alunos papel sulfite, borrachas e lápis para que pudessem construir individualmente textos narrativos, utilizando ou não de fantasia, relacionando suas ideias com a ideia de causalidade de extinção das plantas. Após 20 minutos de construção dos textos, eles foram lidos e então problematizados, passando por questões de meio ambiente e cultura, e também sobre como a causalidade dessa extinção pode ou não estar relacionada ao ser humano.

Por fim foi realizada uma etapa de avaliação dos participantes, após a apresentação da aula. Esta etapa foi gravada para posterior análise. Os interlocutores foram identificados com a letra $\mathrm{P}$ acompanhada de um número de 1 a 6 para expressar cada um em particular.

\section{OS RESULTADOS - as observações dos participantes}

P1: "Bom, parabéns, ficou muito bacana, você conseguiu através da mediação, das perguntas que você vez, estimular os alunos e conseguir que eles resgatassem o conhecimento que eles já tem, o conhecimento prévio deles sobre a situação. Uma sugestão que eu tenho, acho que a única sugestão, é que isso fosse representado depois, porque eu gosto muito de história, falei aqui que gosto de escrever história e tudo mais, mas se fosse representado num teatro depois, junto com o professor de Artes, ia ficar muito, muito bacana." 
P2:“Gostei muito da prática, acho impressionante, achei muito legal quando a gente leu os textos depois, perceber que cada aluno tem uma percepção de mundo diferente e coloca isso no texto. No texto narrativo cada um fala como se fosse o personagem, um fala como a planta que sofreu, cada um conta de um jeito, e acho muito bacana você pegar o que cada um sente, o sentimento interior de cada um, acho muito bacana, as coisas ficaram muito esclarecidas com a mediação."

P3: "Estou impressionada, porque hoje mais cedo a gente tava comentando que precisa de um data-show, de um slide, você provou que não precisa de nada, a não ser você mediando a nossa discussão, muito legal, gostei, e concordo que poderia ter uma representação pra finalizar."

P4: "Parabéns, no museu eu falei, ah, é um texto narrativo, vamos ampliar, mas vi como surgem textos bem diversos aqui, cada um tem um jeito de escrever, achei muito legal isso, também concordo que essa interpretação no final poderia ser legal, algo mais interdisciplinar, mas gostei."

P5: "Parabéns, você utilizou um recurso simples, lápis, papel, e você se preocupou em refletir lá na hora o que cada um falou no seu texto."

P6: "Gostei bastante da dinâmica, e de cada um contar, escrever do seu jeito, que vier na cabeça, mas relacionado ao tema."

\section{A DISCUSSÃO - análise das falas}

Assim como no trabalho de Galvão (2005), foi possível perceber nos textos e na avaliação dos alunos a relação da fantasia da narrativa com os conflitos contemporâneos atuais, que se relacionam com o conceito de extinção de plantas. A potencialidade do método também surpreendeu, porque não se esperava tamanha eficácia como descrito no texto da autora. Alguns alunos, como percebe-se pelas avaliações, se surpreenderam com a estratégia, pois não enxergaram anteriormente as possibilidades que um método de construção tão simples em sala de aula pode oferecer.

Como dito anteriormente, podemos aliar a literatura existente à ferramenta de Texto Narrativo, a ser construído pelos alunos. Por exemplo, seguindo o exemplo de 
Carvalho (2008), poderíamos utilizar os livros de Monteiro Lobato (ou outro autor, após análise prévia do professor) para iniciar uma discussão sobre a Biologia em um contexto literário, seguido pela construção de um Texto Narrativo pelos alunos. Reis Neto et al (2011, p.4) também apontam que "a prática da leitura e escrita oferece ao sujeito uma autonomia maior para o pensamento e oferece um aparato eficiente para a comunicação"

\section{CONSIDERAÇÕES FINAIS}

O Texto Narrativo se mostrou uma estratégia com grande potencial para o Ensino de Botânica e para a Educação Ambiental, e os resultados da prática foram realmente surpreendentes. A maioria dos participantes demonstrou entusiasmo e empenho na construção dos textos, e cremos que isso se reflita em uma sala de aula real, embora certas peculiaridades sejam esperadas neste caso.

\section{REFERÊNCIAS}

BRASIL. Ministério de Educação. Parâmetros Curriculares Nacionais: terceiro e quarto ciclos: Temas Transversais. Secretaria de Ensino Fundamental. Brasília: MEC/SEF, 1998.

CARVALHO, F. A. A biologia em obras infantis de Monteiro Lobato: modulações literárias, científicas e culturais. Ciência e Educação, v. 14, n.3, p. 467-482, 2008.

CARVALHO, J. M. K. ; MACEDO, M. Brincadeiras e Ensino de Ecologia: Subsídios para uma Educação Ambiental Lúdica. In: Seminário Educação 2008, Cuiabá. Anais do Seminário Educação. Cuiabá: UFMT-IE, 2008.

GALVÃO, C. Narrativas em Educação. Ciência \& Educação, v.11, n.2, p. 327- 345, 2005.

MELO, L. Q. ; AMARAL, Z. P.; VIEIRA, R. F. Análise da Diversidade Genética de Arnica (Lychnophora ericoides Less) Usando Marcadores RAPD. In: 52 Congresso Nacional de Botânica, 2001, João Pessoa. Anais de Resumos, 2001.

MINAS GERAIS. Conteúdo Básico Comum (CBC): Ciências do Ensino Fundamental do 6ำ ao 9ำ ano. 2007. Disponível em: http://crv.educacao.mg.gov.br/sistema_crv/banco_objetos_crv/\%7B5FCEB114036C-47C6-B06D-F1F7584AF249\%7D_cbc-ef_ciencias.pdf. Acesso em: 20 de maio de 2014.

NASCIMENTO JÚNIOR, A. F. ; GONCALVES, L. V. Oficina de jogos pedagógicos de ensino de ecologia e educação ambiental como estratégia de ensino na formação de professores. Revista Práxis, v. 5, p. 71-75, 2013. 
OLIVEIRA, A. P. L.; CORREIA, M. D. . Aula de campo como mecanismo facilitador do ensinoaprendizagem sobre os ecossistemas recifais em alagoas. Alexandria (UFSC), v. 6, p. 163-190, 2013.

REIS NETO, J. A. ; ROSA, R. M. ; NASCIMENTO JUNIOR, A. F. Contribuições da escrita literária como estratégia de ensino na formação de professores de ciências e biologia: Análise de um minicurso sobre impactos socioambientais das barragens. In: IV Encontro Nacional de Ensino de Ciências da Saúde e do Ambiente, 2014, Niterói. Anais do IV ENECiências, 2014

SANTOS, F.R. ; PIASSI, L. P. C. WALL-E: O uso de um filme de animação na educação ambiental com temas transversais dos PCN. In: II Simpósio Nacional de Ensino de Ciência e Tecnologia, 2010, Ponta Grossa. Anais. Curitiba: Universidade Tecnológica Federal do Paraná - UTFPR, 2010.

SCHALCH, C. S.; RAMIRES, M.; BARELLA, W. Proposta Lúdica para o Ensino de Ecologia. Revista Ceciliana (online), v. 1, p. 16-21, 2012.

SILVA, M. D. C. A. A utilização da música no ensino de Ecologia: Aquecimento global em questão. In: Semana Universitária da UPE, 2012, Anais, 2012

SILVA, P. R.; CAVASSAN, O. ; CALDEIRA, A. M. de A. Macunaíma, o herói sem nenhum caráter: a obra de Mário de Andrade como recurso para o desenvolvimento de projetos de Educação Ambiental. In: V Encontro Regional Sul de Ensino de Biologia e IV Simpósio Latino Americano e Caribenho de Educação em Ciências, 2011, Londrina. Anais do V EREBIO-SUL e IV ICASE, 2011. 